\title{
LXVIII. On the pressure of the earth against revetements and retaining walls
}

\section{Mr. Thomas Tredgold}

To cite this article: Mr. Thomas Tredgold (1818) LXVIII. On the pressure of the earth against revetements and retaining walls, Philosophical Magazine Series 1, 51:242, 401-404, DOI: $10.1080 / 14786441808637576$

To link to this article: http://dx.doi.org/10.1080/14786441808637576

册 Published online: 27 Jul 2009.

Submit your article to this journal

Џ Article views: 2

Q View related articles $₫$ 


\section{$\left[\begin{array}{ll}401 & 1\end{array}\right.$}

\section{LxVill. On the Pressure of the Earth against Revetements and Retaining Walls. By Mr. Thomas Tredgol.b.}

$I_{r}$ $T$ has besn observed, in making experiments on the strength of tevetements, that the pressure of the earth increases in at certain degree, the stability of the wall*. To account for this increare of stability; the writer of an article on the subject, in the Encyclopedu Metropolitanat, has adopted the method of resolving the force, resulting from the pressure of the earth, that appears to have been first practised by Rondelet $t:$ but this method is evidently inferior to the one used by Coulomb and Prony, as it does not indicate the angle of fracture; consequently does not give the maximum pressure of the earth; and when the cohesion is omitted, it is much inferior even in point of simplicity.

The colsesion of the earth, which is so strongly objected to by the writer above mentioned, is not a necessary appendage to Coulomb's Theory, and would, perhaps, be better left out; also, similar ohjections might be urged against introducing the cohesion of the mortar in calculating the strength of the wall.

But to return to the stability imparted to the wal by the pressure of the earth.- It appears to result parily from friction; as it must be evident no motion could take place without friction against the back of the wall. I will, therefore, attempt to include its effect in an investigation of the pressure of the earth: Let $A B C D$ (Plate IV. fig. 12) represent a section of the wall; and $B D E$ a section of the prism of earth that slides forward in the case of fracture, DE representing the plane of fracture, which we will suppose to be a plane surtace.

Wut $W=$ the weight of the prism of earth acting against the wall.

$\mathrm{R}=$ the resistance of the wall, or the horizontal force that retains the sliding prism on the plane of fracture.

$a=$ the angle which the plane of fracture makes with the horizon.

$f=$ the frietion when the pressure is unity.

$h=$ the height of the wall $=\mathrm{BD}$.

And, $S=$ the weight of a cube of earth whose side is unity.

It is shown, by writers on mechanics, that when a body is sustained upon an inclined plane, and is in equilibrio, the whole force in the direction $\mathrm{ED}$ is $=\frac{W(\sin a-f \cos a)}{\text { radius }}$.

- Col. Pasley's "Course of Military Instruction," vol. iii. chap. xxv.

+ Art. Mechanics, section xxv. part i.

$\$$ L'Art de Bátir, tome ïi. p.125.

Fol. 51. No.242. June 1818.

$\mathrm{C} \mathrm{c}$

This 


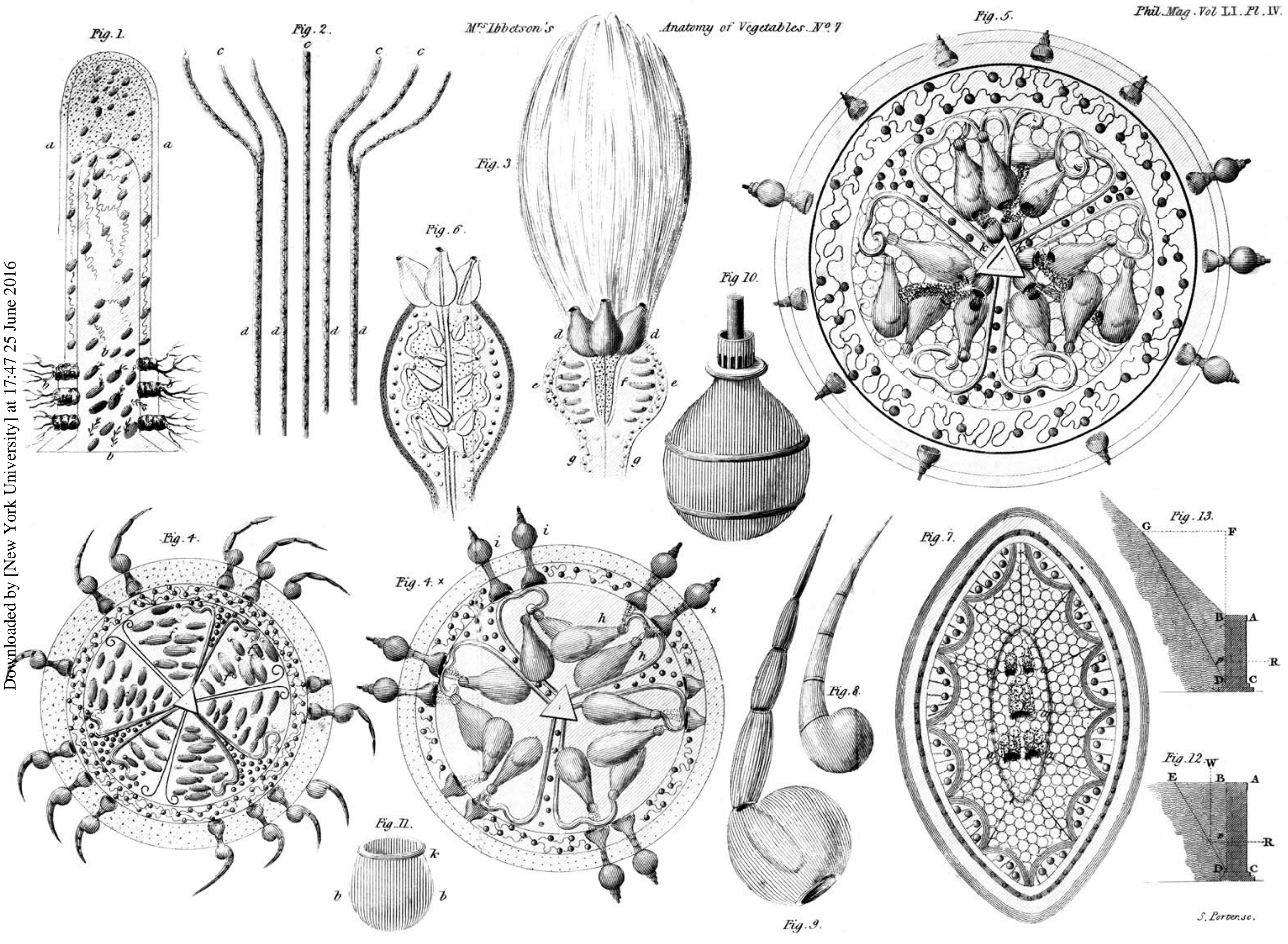




\section{On the Pressure of the Earth against Revêtements}

This force is opposed by the resistance of the wall, which may be supposed to act in a horizontal direction; and whers reduced to the direction $\mathrm{DE}$ it becomes $=\frac{\mathrm{R} \cdot(\cos a+f \sin , a)}{\mathrm{radius}}$.

Also, the pressure against the back of the wall is equal to $\mathrm{R}$; consequently the friction is $=\mathrm{R} f$; and when this force is reduced to the direction $D E$, it is $=\frac{R \cdot\left(f \sin . a-f^{2} \cos , a\right)}{\text { radius }}$. have

And, when the forces $(A),(B)$, and (C) are in equilibrio, we

$$
\text { R. }\left(\cos . a+2 f \sin . a-f^{2} \cos . a\right)=W .(\sin . a-f \cos . a) \text {. }
$$

But, making the radius $=1$, this equation may be put under a form better suited to the present purpose; that is

$$
\mathrm{R}=\frac{\mathrm{W}(\tan \cdot a-f)}{1+2 f \tan \cdot a-f^{*}}
$$

Or, because $\mathrm{W}=\frac{x}{2} h^{2} \mathrm{~S} \times \frac{1}{\operatorname{tap} \cdot a}$;

$$
\mathbf{R}=\frac{\frac{x}{2} h^{2} \mathrm{~S}(\tan \cdot a-f)}{\tan \cdot a+2 f \tan \Omega^{2} a-f^{2} \tan a} .
$$

The second part of this expression becomes a maximum when

$$
\text { tan. } a=f+\sqrt{ }\left(\frac{1+f^{2}}{2}\right) \text {. }
$$

And if the angle which the plane of repose makes with the horizón be denoted by $c$; then $f=\frac{\sin . c}{\cos . c}$; consequently

$$
\text { tan, } a=\frac{\sin c+\sqrt{\frac{\pi}{2}}}{\cos c} \text {. }
$$

If the friction against the back of the wall had been neglected, the expression for the tan. $a$ would have become equivalent to the simple and elegant one obtained by M. de Prony.

The value of the tan. $a(F)$ being introduced in the equation (E), it becomes

$$
\mathrm{R}=\frac{\frac{\pi}{2} h^{2} s}{\sin . c \sqrt{2}+1+\frac{\sin ^{3} c \sqrt{2}+\sin { }^{2} c}{\cos ^{2} c}+\frac{\sqrt{4}}{2 \cos c}} .
$$

But the numeral value of the denominator will be constant for the same kind of earth; and let this value be $=t$;

$$
\text { then } \mathrm{R}=\frac{h^{2} \mathrm{~S}}{2 t} \text {. }
$$

And as the wall may either slide on its base, or turn on the point $\mathrm{C}$ as a centre of motion; it may be shown, that in the latter case, the leverage $\mathrm{D} p=\frac{1}{3} h$.

The preceding inquiry extends only to retaining walls, counterscarp revetements, terrepleins without parapets, \&c. But a simple 
simple case of partial searp revetements presents itself, which it would be as well to consider.

Suppose the revetement (fig. 13) to have a berm $A B$ equal to the breadth of the top of the wall, and that the plane of fracture produced would intersect the earthen scarp at $\mathbf{G}$; also let $h^{\prime}$ be the height of this point above the top of the wall $=$ FB ; $h$ being the height of the vall as before. It is obvious that the equation (D) still expresses the conditions of equilibrium; that is,

$$
\mathrm{R}=\frac{\mathrm{W} \cdot(\tan a-f)}{1+2 f \tan , a-f^{4}} .
$$

But if $U$ be the angle which the front of the scarp BG makes with the horizon; then by supposition $\frac{h+h^{l}}{\tan \cdot a}=\frac{h^{\prime}}{\tan .6}$; therefore $\mathrm{W}=\frac{T}{2} h \mathrm{~S} \frac{h+h^{\prime}}{\tan . a}$. And as this change in the value of $\mathrm{W}$ will not affect that of the angle of fracture in any considerable degree, it may be neglected; in which case

$$
\mathrm{R}=\iota \mathrm{S} \frac{h+h^{\prime}}{2 t} \text {. }
$$

Hence the leverage becomes $\mathrm{D} p=h \frac{2 h+3 h^{\prime}}{6\left(h+h^{\prime}\right)}$, and the value of $h^{\prime}$ is $=\frac{k \tan . b}{\tan . a-\tan . b}$.

But in the actual construction of revêtements the angle $b$ is generally $45^{\circ}$, and in that case $h^{\prime}=\frac{h}{\tan \cdot a-1}$; consequently

$$
\mathrm{R}=h^{2} \mathrm{~S} \frac{\tan \cdot a}{2 t(\tan \cdot a-1)}
$$

$$
\text { And, } \mathrm{D} p=h \frac{2 \tan \cdot a+1}{6 \tan \cdot a} \text {. }
$$

The equation $(\mathrm{K})$ might be applied to demirevetements, and to partial revêtements in general, where it would be accurate enough. for practical purposes: and it must be remembered that the old methods fail completely when applied to these revetements.

According to the principles I have endeavoured to point out, it appears, that when the earthen scarp exceeds the height $h^{\prime}$, it might be raised to any height without itiereasing the pressure against the wall; as is indicated by the experiments of Col. Pasley*. But if we suppose (with Belidor, Rondelet, \&c. \&c.) that the angle of fracture coincides with the natural slope of the earth; and also that the inclination of the earthen scarp $B G$ (fig. 13) is the same as the natural slope (which is generally taken at $45^{\circ}$ ) ; it is obvious that the pressure ought to increase with the height of the earthen scarp, without linit.

" "Course of Military Instruction," vol. iii. chap. xxy.

$$
\mathrm{C} \varepsilon 2
$$


This, however, is directly contrary to the results of the expe-riments above quoted, and to the experience of every practical man, who has been guided by the intuitive suggestions of his own feelings in preference to the rules of mechanieal writers.

:0, Bentinck-street, May 25, 1818.

LXIX. On the Seeds of Plonts. By Mrs. Agnus Ibbetson.

\section{To Mr. Tilloch.}

$\mathrm{s}_{\mathrm{I}, \mathrm{H}}-\mathrm{M}$ Y object, it is well known, is to simplify my subject, render the real knowledge of the form and nature of plants easy; to furnish the means of comparing together the analysis of their resemblance and their differences; and by these means assign to each part a name, that may recall not only an appellation, but the idea of their properties and qualities, and what situation. each part should hold in their general character in the vegetable uorld, when compared with the animal creation.

To show the formation of a plant by taking plants up progressirely from the ground, and then dissecting them in their increase. must appear (I should suppose) of all means the most exact ami conclusive; since one specimen becomes inevitably the correction of the preceding ones.

It is certainly the most exact mothod of understanding the formation of a plant, though it was never before known that a vegetable could be so taien: but common serse shows, that if the last part can be examined progressively and outwardly, the first should be sought in the, same manner, in its regular process in the interior; and if every part of a plant assimilates with the animal creation in so exact a manner interiorly, is it likely it should differ in so essential a point as to form its progemy or seed between the skins? Is there a single instance in nature of such a formation, either animal, reptile, or insect tribe? the latter of which so much resembles plants. In my last letter I again brought forward that curious circumstance of which each dissection confirms the truth, and which forms a most beautiful and simple delineation of the construction of vegetable nature: I mean the fact "that the cotculum of the seed is protrurled in the root." It has been said that I assert "that the seed is formed there." I appeal to my various letters in this work and in Nicholcor's Journal, for the refutation of this charge; proving there positively, that I never advanced such a proposition. No two things can be more different than the corculum of the seed and the seed itself; the first being inserted within the second in the 